\title{
Vitamin D effectiveness and pathology in humans and domestic animals
}

\author{
Hayder Kamil Maryoosh Alabada ${ }^{\mathrm{ab}}$ and Wessam Monther Mohammed Saleh ${ }^{\mathrm{a}}$ \\ aDepartment of Internal and Preventive Medicine, College of Veterinary Medicine, University of Basrah, Basra State, Iraq. \\ bDepartment of Livestock Services, Al-Diwaniyah Agriculture Directorate, Ministry of Agriculture, Iraq.
}

ABSTRACT Vitamin D is a fat-soluble vitamin that involved mainly for intestinal absorption of calcium with the regulation of calcium/phosphorus hemostasis, bone formation and remodeling, and anti-inflammatory with immune-modulating advantages. Insufficient solar UVB irradiation and/or lack of vitamin D in diet could induce a deficiency of vitamin $D$ in animals and humans that manifested by poor appetite and growth and consequently leads to osteomalacia and osteodystrophy. A wide range of non-skeletal disorders, neoplastic, cardiovascular, and autoimmune diseases are attributed to vitamin $D$ deficiency. This current review is presenting an overview of the origin/source, metabolism and activation, biology, physiology and functions, and the pathology of vitamin D in human and domestic animals. Special topics of vitamin D deficiency, toxicity, and rickets are also detailed in this review. In conclusion, maintenance of a normal serum level of active form of vitamin $D$ prevents the occurrence of broad ranges of disorders and diseases. Beside enhance the weight gain and the growth of the growing animals, normal levels of vitamin D may also play a crucial role as immune-modulating factors for making animals and people resistant against contagious diseases such as hemorrhagic septicemia and coronavirus (COVID-19).

KEYWORDS 1,25-dihydroxycholecalciferol; ergocalciferol; rickets; vitamin D deficiency

Accepted article April 20, 2020 Published online April 29, 2020

Cite this article: Alabada HKM, Saleh WMM (2020) Vitamin D effectiveness and pathology in humans and domestic animals. Multidisciplinary Reviews 3: e2020010. DOI: $10.29327 /$ multi. 2020010

\section{Eficácia e patologia da vitamina D em humanos e animais domésticos}

RESUMO A vitamina D é uma vitamina lipossolúvel que envolve principalmente a absorção intestinal de cálcio com a regulação da hemostasia de cálcio/fósforo, formação e remodelação óssea e anti-inflamatório com vantagens de modulação imune. A radiação solar UVB insuficiente e/ou a falta de vitamina $D$ na dieta podem induzir uma deficiência de vitamina $D$ em animais e humanos que se manifesta por falta de apetite e crescimento e, consequentemente, leva a osteomalácia e osteodistrofia. Uma ampla gama de doenças não esqueléticas, doenças neoplásicas, cardiovasculares e autoimunes são atribuídas à deficiência de vitamina D. Esta revisão de literatura apresenta uma visão geral da origem/fonte, metabolismo e ativação, biologia, fisiologia e funções e patologia da vitamina $D$ em animais humanos e domésticos. Tópicos especiais em deficiência de vitamina $D$, toxicidade e raquitismo também são detalhados nesta revisão. Em conclusão, a manutenção de um nível sérico normal da forma ativa de vitamina $D$ impede a ocorrência de amplas faixas de distúrbios e doenças. Além de aumentar o ganho de peso e o crescimento dos animais em crescimento. Os níveis normais de vitamina $D$ também podem desempenhar um papel crucial como fatores imunomoduladores para tornar os animais e as pessoas resistentes a doenças contagiosas, como septicemia hemorrágica e coronavírus (COVID19).

PALAVRAS-CHAVE: 1,25-di-hidroxicolecalciferol, ergocalciferol, raquitismo, deficiência de vitamina D 


\section{Introduction}

Vitamin D (as written D2 or D3) is a major member of the fat-soluble vitamins which endogenously be produced through exposure of skin to direct sunlight, or it is mainly absorbed from food containing or supplemented with vitamin D (Abboud et al 2017). However, vitamin D plays an initial physiological role by maintaining the extracellular ions of calcium in the body, which is essential for the functioning of many neuromuscular activities and metabolic processes (Holick 2002).

As described here in this review, vitamin D is referring secosteroids ergocalciferol "Vitamin D2" and colicalceferol "Vitamin D3". Vitamin D2 is produced by UVB radiation ofergosterol, that it is frequently found in vertebrates, fungi and plants. Despite vitamin D3 has the same genesis like vitamin D2; the pro-vitamin is 7-dehydrocholicalceferol which is particularly found in vertebrates. Vitamin D3 is also formed in humans by exposure the skin to sunlight (Holick 2007).

After synthesized in the skin and/or after its absorption in the alimentary tract, vitamin D3 is transported to liver and bound in blood circulation with vitamin-D-binding. Then in liver, ithydroxylated to form the" 25 hydroxycholecalciferol" that formerly named $25(\mathrm{OH})-\mathrm{D}-3$ or "Calcidiol" at rate relating to the substrate supply (Ball 2013). However, 25(OH)-D-3 is the main circulatory metabolite of vitamin D3, and its concentration in blood is used as an indicator of vitamin D status (Holick 2002; Holick 2007; Ball 2013). Consequently in kidneys, 25(OH)-D-3 is activated by second hydroxylation to form the "1,25-dihydroxycholecalciferol" that formerly named [1,25(OH)2-D-3] or "Calcitriol". This product is tightly being regulated through: Calcium by Parathyroid Hormone (PTH) and Phosphorus by Fibroblast Growth Factor 23 (FGF 23) as well as during growth and pregnancy (Holick 2007; Mason et al 2011; Quarles 2012). Then the products 25(OH)-D-3 and 1,25(OH)2-D-3 be catabolized and excreted through bile (Ball 2013).

The target organs or tissue of "1,25(OH)2-D-3" are bones, kidneys, intestine, and the Parathyroid glands; where it performed hormonal functions where it carries out hormonal functions. With the action of Parathyroid Hormone, the major function of vitamin D is for maintaining plasma ionized Phosphorus and Calcium concentrations within slight physiological border (Dusso 2005).

Vitamin D3 metabolite (1,25(OH)2-D-3) acts as a regulating hormone of Calcium and Phosphorus metabolism for maintaining their concentrations in serum to ensure normal mineralization of bones. Moreover, vitamin $D$ probably plays a role in development of muscles based on the receptors of vitamin D are located in muscles and muscle weakness occurs in vitamin D deficiency. Further tissues have vitamin D receptors such as colon, breast, prostate, immune cells and brain (Holick 2007; Ball 2013).

This current review is presenting an overview of the origin/source, metabolism and activation, biology, physiology and functions, and the pathology of vitamin $D$ in human and domestic animals.

\section{Chemical structure of vitamin D}

As explained earlier, vitamin D exists in two main forms: vitamin D3 "Cholecalciferol" and vitamin D2 "Ergocalciferol". When it is written without a subscript the designation vitamin D denotes either D2 or D3. UVB rays of sunlight cleave the (B) ring between Carbon 9 and 10 opening the ring to create an asecosteroid structure (Figure 1). In this process, the pro-vitamin molecules precursor (7-dehydrocholesterol in animals and ergosterol in plants) are transformed to the secosteroids, Vitamin D2 and Vitamin D3 (Feldman et al 1997). These two secosteroids are varying by the presence of methyl group at Carbon 28 and double band between carbons 22 to 23 on the chain side of Vitamin D2. Both Vitamins D2 and D3 are identically handled in the body and transformed by two hydroxylation steps for activation the hormones; 1,25(OH)2D2 or 1,25(OH)2D3 (Feldman et al 2013).

\section{Sources of vitamin D}

Human and animals can mainly get Vitamin D from direct exposure to the solar UVB light, from diet and from supplementation (Holick 2006a). High oily fish diet will commonly prevent Vitamin D deficiency (Bouillon 2001). Solar UVB radiation at wavelength 290-315 nm penetrates the skin converting the complex "7-dehydrocholesterol" to previtamin D3, which is directly converted to Vitamin D3. However, excessive exposure to UVB light does not cause Vitamin D3 intoxication because any extra pre-vitamin D3 and Vitamin D3 are destroyed by UVB light (Holick 2006a). Little diets 
naturally contain and/or enriched with "Vitamin D" as D2 or D3. As we stated earlier, vitamin D2 is formed by the UV irradiation of Ergosterol from yeast, while Vitamin D3 is synthesized by the UV irradiation of 7-dehydrocholesterol from lanolin (Holick 2007).

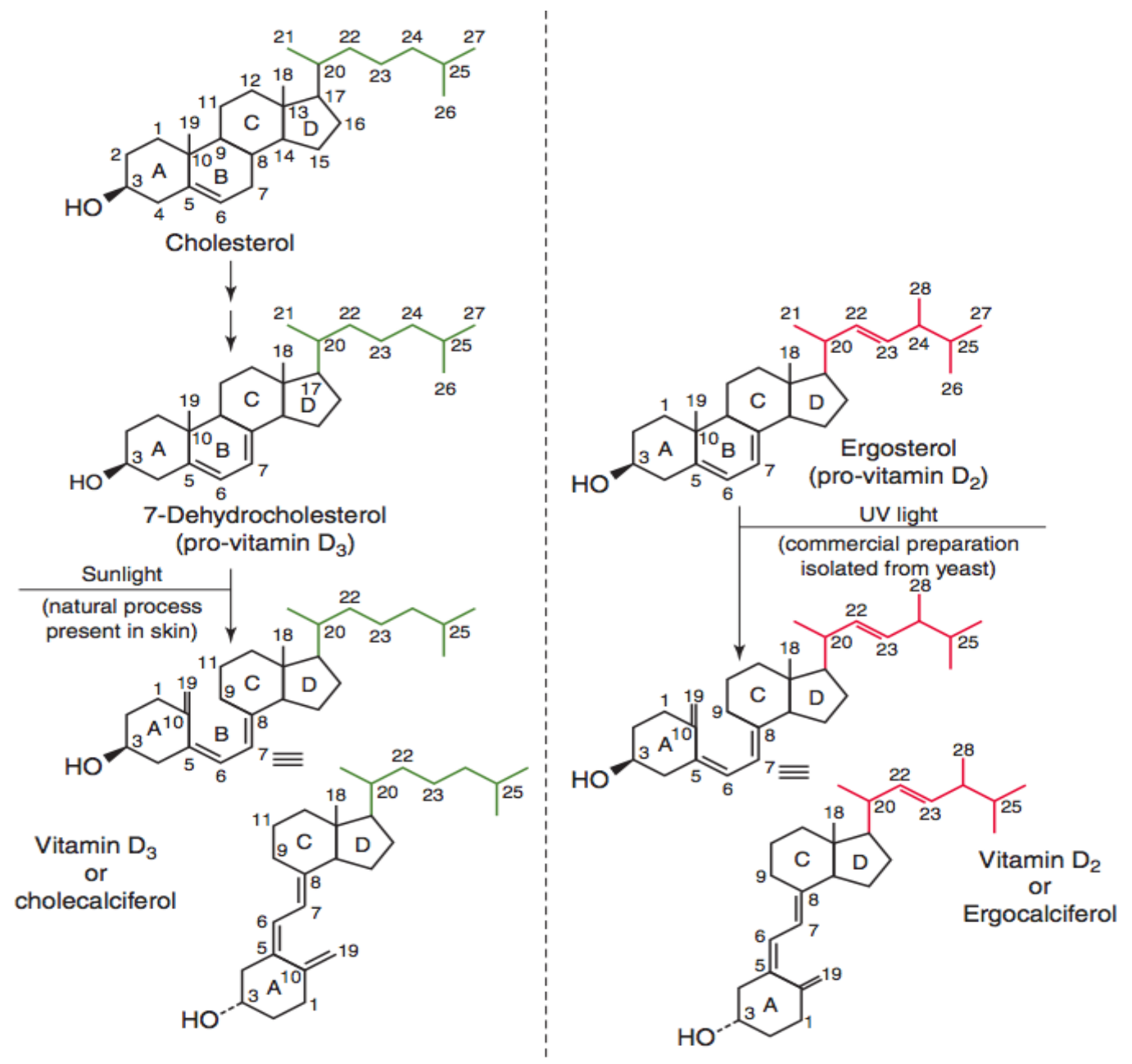

Figure 1 The chemical structure of vitamin D. Source: https://vitamind.ucr.edu/about

The major Vitamin D source for the ruminants is through dermal photo-conversion of 7-dehydrocholesterol to Cholecalciferol by UV irradiation (Hidiroglou et al 1979). Thus, with intensive animal husbandry especially in Northern Hemisphere, sheep must be fed by dietary or supplementary Vitamin D to reach their requirements. Reduced daily dietary intake of Vitamin D combined with low exposure to sunlight can contribute to the sharp reduction of this vitamin (Hidiroglou et al 1984).

Additionally, Vitamin D can also be maintained from feed source or endogenously be synthesized as Vitamin D3 Vitamin $D$ following photo-conversion of the 7-dehydrocholesterol, which located in epidermal Keratinocytes and the dermal Fibroblasts by UVB irradiation (Elder and Bishop 2014). Nutritional form of Vitamin D consists of plant-derived Vitamin D2 or D3 which is mainly found in fish oil, liver and eggs (Handel et al 2016).

\section{Metabolism and activation}

Two successive hydroxylation reactions are activating Vitamin $D$ to its hormonal form, 1a,25-dihydroxyvitamin D3 $(1,25(\mathrm{OH}) 2 \mathrm{D} 3)$. The first one takes place in liver tissue, resulting in 25-dihydroxyvitamin D3 (the active metabolite of Vitamin D3). Then it is converted in the kidney to 1,25dihydroxyvitamin D3 by the renal cytochrome p450 enzyme, 25hydroxyvitamin D3-1ahydroxylase (CYP27B1, mentioned as 1a-OHase). The kidneys are the main site of 1s-OHase 
activity, thus, gene expression of 1a-OHase has been detected in other types of cells including; osteoblasts, chondrocytes, macrophages and keratinocytes (Jones et al 1998; Miller and Portale 2000).

\begin{tabular}{|l|l|l|l|}
\hline Environment & Gravity & Calcium & $\begin{array}{l}\text { Bone } \\
\text { Remodeling }\end{array}$ \\
\hline Aquatic & Low & High & Low \\
\hline Terrestrial & High & Low & High \\
\hline
\end{tabular}

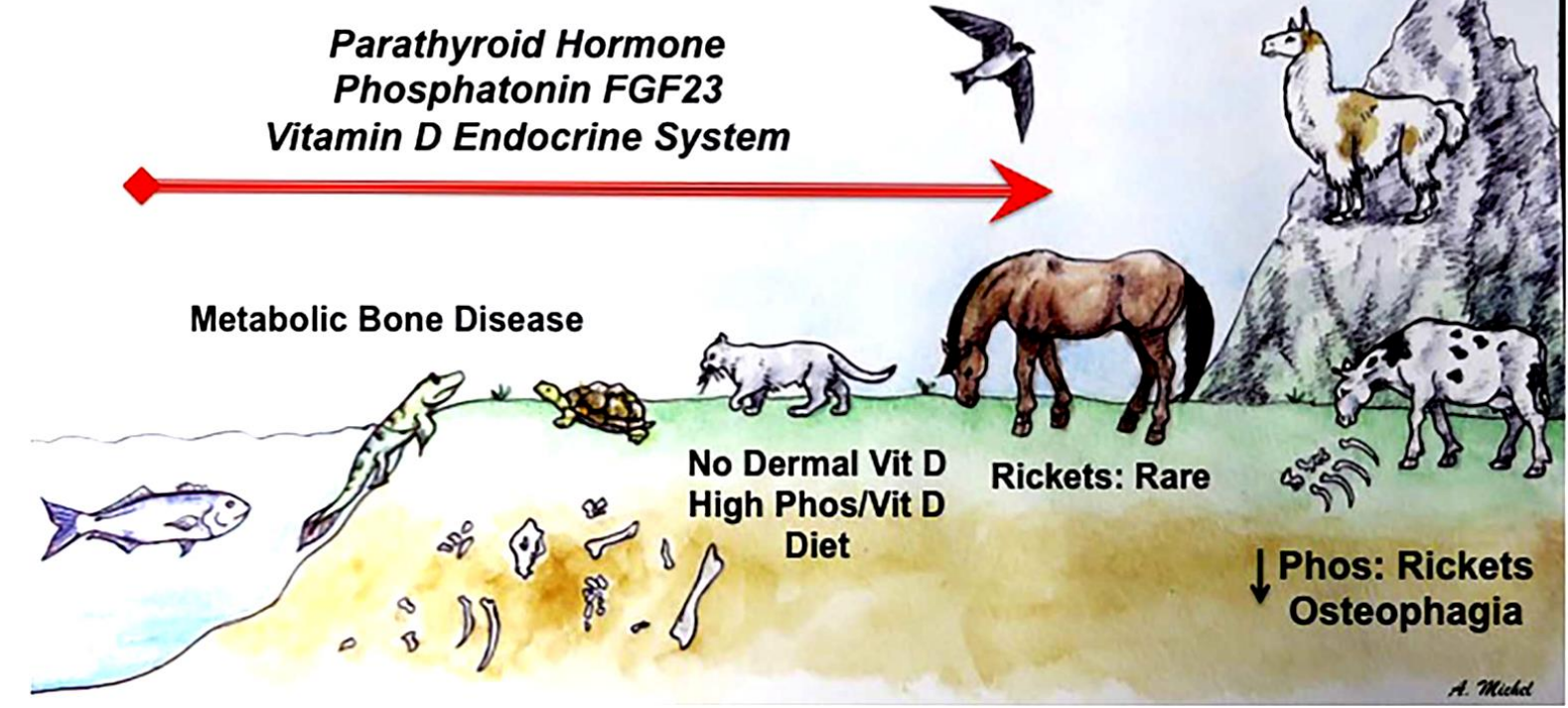

Figure 2 Evolution of calcium and phosphorus hemostasis in species susceptible to vitamin D deficiency and/or Rickets. The major $\mathrm{Ca} / \mathrm{P}$ metabolism mediators evolved originally in fish, but they were reused during land environments colonization. Additional adaptation to a diversity of diets/environments across the species has created a variety susceptibility to vitamin D deficiency and rickets. Source: Uhl (2018)

Once 1,25-dihydroxyvitamin D3 be synthesized, it plays a key role in the regulation of Calcium hemostasis through boosting Calcium absorption from the intestine. Both 1,25-dihydroxyvitamin D3 and Parathyroid Hormone are involving the homeostatic feedback loop. Blood Calcium decrease stimulates production and secretion of Parathyroid Hormone leading to increase expression of 1a-OHase gene, 1,25-dihydroxyvitamin D3 synthesized and intestinal Calcium absorption. Avoiding sustained production of 1,25-dihydroxyvitamin D3 that could lead to Hypercalcemia, Vitamin D hormone inhibits Parathyroid Hormone and 1a-OHase gene expression (Heaney 2005).

\section{Vitamin D functions}

The main target tissues and organs of Vitamin D are the bones, intestine Kidneys, and Parathyroid glands (Dusso 2005). With parathyroid hormone, the essential function of Vitamin D is for maintaining the plasma ionized Calcium and Phosphorus levels within tight physiological limit.

\section{Intestine}

The 1,25-dihydroxyvitamin D3 enhance active uptake and trans-cellular conveyance of Calcium in the intestine. The epithelial Calcium canal, Transient Receptor possible Vanilloid 6 (TRPV6), transmission Calcium to the cell where it bind to "calbindin D" then is transferred across the cells (Suzuki et al 2008). The "TRPV6" is strongly Vitamin D dependent with Calcium influx that interacts with Calbindin-D9K, which considered as a main rat-limited step in the process of Vitamin D dependent active Calcium absorption. However, a Ca2p ATPase (PMCA1b) andNap/Ca2p exchanger (NCX1) discharges Calcium to blood (Bouillon et al 2003) and transport of paracellular Calcium down an electrochemical 
gradient is also occurred (van Abel et al 2003). Calbindin and TRPV6 are up-regulated by 1,25-dihydroxyvitamin D3, whereby increasing intestinal Calcium absorption (Meyer et al 2006). In contrast, higher blood Calcium concentration provides negative response on the numbers of TRPV6 channels, that decreasing intestinal Calcium absorption (Hoenderop et al 2005). Calbindin and TRPV6 are also be stimulated (regardless of Vitamin D \& blood calcium concentration) by height dietary and intestinal Calcium concentration (van Abel et al 2003). Active Phosphorus absorption might also be positively influenced by 1,25-dihydroxyvitamin D3, leading to increase expression of the Na-Pi transporters which alters the composition of the intestinal cell membrane (Yagci et al 1992).

\section{Bone remodeling}

In the bones, 1,25-dihydroxyvitamin D3 combined with Parathyroid Hormone, raises mobilization of Calcium from its bone stores maintaining a narrow range of ionized blood Calcium concentration (Holick 1999). This process is thought to be performed through activation of "RANKL", a receptor activator of NF-kB ligand, and excess Osteoclastogenesis (Anderson and Atkins 2008). Moreover, RANKL (a surface ligand on the osteoblast) could binds to osteoclasts either by RANK (a receptors activator for NF-kB) or by a decoy receptor named Osteoprotegerin (OPG) (Suda, 2003). While RANKL binds RANK, a differentiation and maturation for osteoclast progenitor cells to osteoclast are induced (Takeda et al 1999). RANKL is activated by 1,25-dihydroxyvitamin D3 through VDREs on the promoters of RANKL, whereby inducing Osteoclastogenesis, bones resorption and mobilization of Calcium (Kitazawa et al 2003). Osteoprotegerin production is inhibited by 1,25-dihydroxyvitamin D3 (Kondo et al 2004), whereas RANKL binds to Osteoprotegerin, Osteoclastogenisis and bone resorptions are inhibited (Boyce and Xing 2008).

\section{Bone growth and mineralization}

It is questionable whether Vitamin D impact directly or indirectly growth of bone and mineralization by changing Calcium and Phosphorus concentrations in the extracellular fluids through intestinal absorption of Calcium (Takeda et al 1999). If ionized Calcium and Phosphorus levels are within the normal physiological limits, 1,25-dihydroxyvitamin D3/Vitamin D Receptor (VDR) is apparently not crucial for mineralization Osteoid (Panda et al 2004). Thus, osteoblast and chondrocytes express both VDR 25-hydroxyvitamin D-1ahydroxylase (St-Arnaud 2008). Both calcium and 1,25dihydroxyvitamin D3, which VDR independent, are believed that required to natural-growth plate development (Goltzman et al 2004).

A study conducted on juvenile mice with inactivated vitamin $D$ receptor in chondrocytes have affect vascular intrusion and reduced osteoclast membrane, influencing transient increases in the thickness of the essential Spongiosa (Masuyama et al 2006). Likewise, the mice, which suffered from "chondrocyte-particular inactivation" of 1ahydroxylase, have also weakened the vascular intrusion with raised neonatal bone volume, additionally to increase the width of the hypertrophic area of the growth plates (Naja et al 2009). These mice experiments had an intracrine action of 1,25-dihydroxyvitamin D3 in endochondral ossification, furthermore the endocrine part of maintaining serum Calcium and Phosphorus within the normal limit.

\section{Parathyroid glands}

The 1,25-dihydroxyvitamin D3 and VDR are not vital for controlling Parathyroid Hormone production, however, they do not work conjugating with Calcium (Dusso 2005). Vitamin D deficiency occurs in hypocalcemia, which could cause parathyroid hyperplasia with secondary hyperparathyroidism (Milgram 1990). In contrast, 1,25-dihydroxyvitamin D3 restrained parathyroid cell growth via reducing growth factors [converting growth factor, epidermic growth factor receptors growth loops] and rising the known inhibitor of cells growth [cyclin-dependent kinase inhibitor p21\&p27] (Dusso et al 2004). All above is the physiological basis for using the active Vitamin D in a patient's treatment with secondary hyperparathyroidism in the late-step of chronic kidney disease (Wolf and Thadhani 2007). Furthermore, active Vitamin $D$ has been exhibited to up-regulate calcium-sensing receptors via binds to VDREs on the Calcium-sensing receptors gene booster. Which leads to increase in the sensibility of the Parathyroid Gland to plasma ionized Calcium and reduction of Parathyroid Hormone excretion (Canaff and Hendy 2002). 


\section{Parathyroid glands}

The chief role of 1,25-dihydroxyvitamin D3 in the kidneys are to control their production through suppression of renal 1a-hydroxylase suppression combined with stimulation of 24-hydroxylase (CYP24) (Dusso 2005). It is controversial whether 1,25-dihydroxyvitamin D3 has directly affect the renal infiltration of Calcium and Phosphorus, on condition its effect is unclear by its action on Parathyroid Hormone and intestinal Calcium and Phosphorus absorption (Zittermann 2003). Moreover, calcium transports through the renal and intestinal epithelial cell are same.

The Epithelial Calcium canal "TRPV5" is presents on the Apical cells layer of the distal twisted tubules (DTT) which summation ducts of kidney transporting Calcium to the cells (Suzuki et al 2008). Thus, the Calbindin-D28K transport Calcium through the renal tubular cells, and the Calcium carriers NCX1 and PMCA1b on the baso-lateral cells membrane is released Calcium to the stream of blood (Boros et al 2009). All of Parathyroid Hormone, 1,25-dihydroxyvitamin D3 and estrogen independently might induce up-regulation of TRPV5, Calbindin- $\mathrm{D}_{28} \mathrm{~K}, \mathrm{NCX} 1$ and PBCA1b gene expression (van Abel et al 2002). PTH-dependent Calcium in DCT might be also accelerated by 1,25-dihydroxyvitamin D3 (Holick 1994). It's improbably to be a straight effect on the kidneys, Phosphorus renal tubular reabsorption is raised in the presence of Parathyroid Hormone (Dusso 2005).

\section{Other significant effects}

Other endocrine and autocrin-paracrine roles of Vitamin D in organs and multiple types of cells have been also shown. Vitamin D may have the ability to cure cancer with the possibility of treating cancer through cell growth suppression (Zittermann 2003). In related study, the concentration of Vitamin D and the occurrence of few types of cancer were shown reversely be related, despite of the presence of many confusing factors (St-Arnaud 2008). Another considerable role of Vitamin $D$ is in the immunity; it might be involved in the prevention of cardiovascular disorders, high blood pressure and diabetes mellitus. Vitamin $D$ is also assist in the treatment of inflammatory bowel disease, psoriasis, multiple sclerosis and rheumatoid arthritis (Bikle 2009).

\section{Vitamin D receptors (VDR)}

Vitamin D receptors are members of the family of type II nuclear receptors for steroidal hormones. Heterodimerization and retinoid $X$ receptors [RXRs] are required for these receptors to raise their partiality for the ligand-in this case, 1,25-dihydroxyvitamin D3 (Barsony and Prufer 2002). Vitamin D receptors protein includes four basic domains: 1-bind to ligand 2- Heterodimerization with the RXR 3- Binding of the VDREs 4- Enlistment of coregulators (Dusso 2005). Inside the nucleus, VDR-1,25-dihydroxyvitamin D3 binds to the specified sequences named VDREs which existing in the promoter region of the target gene (Kimmel-Jehan et al 1999). However positively or negatively, nuclear co-activators and transcription factors react with the VDR-RXR-1,25-dihydroxyvitamin D3 to raise or suppress 1,25dihydroxyvitamin D3 activation to gene transcription (Rachez and Freedman 2000).

\section{Physiology of Vitamin D}

The conventional eminent function of Vitamin $D$ is regulation of Calcium hemostasis, which is maintained mostly by bone formation and resorption (Reichrath et al 2003). In addition, hemostasis is maintained via the interaction of Vitamin D with the tissues of Parathyroid gland, kidneys and intestine (Hendy et al 2006). Vitamin D can be endogenously synthesized in skin through UVB irradiation or can be orally ingested (Holick 1994). Vitamin D3 is metabolized from both sources in the liver to 25 -hydroxyvitamin $\mathrm{D}[25(\mathrm{OH}) \mathrm{D}]$ which is the main circulating active form of Vitamin $\mathrm{D}$. This form is probably the one measured by the clinician to estimate the concentrations of Vitamin $D$ in patients. Thus, 25hydroxyvitamin $\mathrm{D}$ is biologically inactive and additional hydroxylation inside the kidney is required forming the active biological derivative of Vitamin D, 1,25-dihydroxyvitamin D3.

The 1,25-dihydroxyvitamin D3 is a liquid soluble hormone interacting with its VDRs in small intestine. Its physiological actions lead to stimulate the epithelial Calcium channel expression, the Calcium-binding proteins and 
numerous other proteins that maintain moving of Calcium from intestinal lumen to bloodstream. 1,25-dihydroxyvitamin D3 is also interfere with VDRs on Osteoblast, which enhance the outflow of the receptor-activator of the nuclear agent $\mathrm{kB}(\mathrm{NFkB})$ ligand "RANKL". These all above result in cascading effects which facilitate the maturation of Osteoclast precursor to Osteoclast, which otherwise, mobilize Calcium stores from bones to sustain Calcium hemostasis (Holick 2006b).

The 25-hydroxyvitamin-D3-1-a-hydroxylase which Transforms 25-hydroxyvitamin D3 to 1,25-dihydroxyvitamin D3 in kidneys is likewise in the activated macrophage and dendritic cells (Fritsche et al 2003). While unlike to the renal cell, the enzyme in the antigen which found in cells is non-responsive to suppress by Parathyroid Hormone or 1,25dihydroxyvitamin D3. However, it is intractable in the cell through a numbers of factors like Interferon c (IFNc) and is down-regulated as matures dendritic cells (Freeman et al 2003).

\section{Pathology of vitamin}

\section{Vitamin D deficiency}

Vitamin D deficiency in is commonly induced by insufficient sunlight exposure or decreases its concentration in diet. It is characterized by poor appetite, lack of growth and in developed cases by Osteodystrophy. Lack of achieved Vitamin D complex in feed prompts an insufficiency of Vitamin D in the tissue (Radostits et al 2007).

\section{Epidemiology}

Vitamin D deficiency happens almost due to decrease exposure of animal as well as human to ultraviolet (UVB) sunlight. Pastures supply very small concentrations of vitamin $D$ and nearly all of the vitamin $D$ feeding of ruminants it coms from synthesis of cholecalciferol in the skin by the activity of the UVB ingredient of sunlight on 7-dehydrocholesterol. Sunlight include a comparatively little component of $W$ light of the short wavelength, which is efficient in vitamin $D$ synthesis (Abbott 2018). The active UVB component is decrease by passing through the atmosphere and when the angle of the sun is increased, the more it gets the distance through the atmosphere which the rays must through itbefore beat the earth. Based on that, the effectiveness of sunlight for vitamin D synthesis is upper when the sun is most directly and when there are no absorbtions to light transmission (McDowell 2000).

Grains, oilseeds and short growing pastures contain very modicum amount vitamin D. As plants ripen and the leaves become pale in tint, UVB light have capable of permeate the leaves and cause diversion of ergosterol to ergocalciferol. Therefore, the leafy hay have a high level of vitamin D2 when it exposure to copious sunlight and that lead to became it dried (Smith and Wright 1985). Lucerne hay is a good source for vitamin D. It contains dead and ripe leaves and has been well exposed to sunlight. Animals feed when it exposure to sun light is little, vitamin D2 is efficient, but vitamin D3 is more effectively utilized by ruminants than vitamin D2 (McDowell 2000).

\section{Pathogenesis}

Vitamin $D$ is a compound of materials with anti-Rachitogenic activity. The main compound is the Cholecalciferol or Vitamin D3 which synthesized as described in section 2.3 (Sources of Vitamin D). Another substantial substance is Vitamin D2 that presents in "sun-cured" hay and is produced via UV irradiation of plants sterols. Calciferol" or viosterol" is commercially manufactured by yeast irradiation and used as dietary supplement. Additionally, ergosterol is the provitamin of vitamin D4 and Ds naturally produced in some fish oils. When the dietary or the naturally produced Vitamin D transported to the liver, the25-hydroxyvitamin D3 is produced and then moved to kidneys where at least two extra derivatives be synthesized via 1-a-hydroxylase (Engstrom et al 1987). One is 1,25-dihydroxyvitamin D3 [DHCC] and the another is 24,25-dihydroxyvitamin D3 [24,25-DHCC]. The form 1,25-dihydroxyvitamin D3, the metabolic form of Vitamin $D$, is produced when there is deprivation or needed of Calcium.

Hence, it appears that 1,25-dihydroxyvitamin D3 is more activein eliciting intestinal Calcium transport/absorption that impacts bone mineralization. It also acts in the regulation of Phosphorus ion absorption/metabolism when particularly it loss in kidneys. Pathologically, 1,25-dihydroxyvitamin D3 deficiency occurs in animals with renal diseases, what causes decreased Calcium Phosphorus absorption, decreased bone mineralization and immoderate loss of minerals by kidneys. Vitamin D deficiency is per se regulated in its significance via the Calcium and Phosphorus state of 
the animals. Because the need of converting Vitamin D into its active metabolite, there is a lateness interval of two to four days after parenteral of vitamin before occurring the considerable of Calcium and Phosphorus absorption. Using of synthetic analogs of the metabolite like 1-a-hydroxycholecalciferol (an analogs of 1,25-dihydroxyvitamin D3) can increase Phosphorus and Calcium in serum during 12 hours post administration, which suggested for the control of Parturient Paresis in cattle (Mason et al 2011; Glorieux and Pettifor 2014; Constable et al 2017).

\section{The maternal status}

The maternal status of Vitamin $\mathrm{D}$ is of valuable for estimating the neonatal plasma Calcium levels. There is a considerable relationship among maternal and neonate calf serum concentrations of 25-OH-D2, 25- $\mathrm{OH}-\mathrm{D} 3,24,25-(\mathrm{OH})-$ D2 and 24,25-(OH)-D3. This suggests that the status of Vitamin D metabolites in the neonate is dependent essentially on the 25-OH-D condition of the dam (Goff et al 1982). However, the maternal serum concentrations of Phosphorus, Calcium and Magnesium are not determined these minerals concentration found in neonatal calf. The capacity of placenta for maintaining the raised plasma Phosphorus or Calcium in the embryo is dependent partly on maternal 1,25dihydroxyvitamin D3 state. Pre-parturition treatments of sows by parenteral Cholecalciferol are an efficient way for nutrition's neonatal piglets with Cholecalciferol through placental transportation (Goff et al 1984).

\section{Calcium:Phosphorus ratio}

When the Calcium: Phosphorus proportion is higher from the normal (1:1 to $1: 2$ ), Vitamin $D$ requirements for optimum Phosphorus and Calcium absorption and mineralization of bones are elevated. A little grade of deficiency of Vitamin D in an environment providing with Calcium and Phosphorus imbalance may induce the disease, while the same grade of deficiency for this vitamin with a naturalistic Phosphorus and Calcium could go unsuspected. In growing pigs for instance, Supplementation of Vitamin D is not fundamental provided Phosphorus and Calcium intakes are strictly controlled, however under workable conditions, these might not be applicable.

The efficiency of food utilization and a Calorigenic action are the minor functions of Vitamin D, and therefore, the rate of metabolism been reduced when there is a lack of Vitamin D. These negative effects are possibly the basis of depressed rate of growth and output in deficiency of Vitamin D. Few index have proved that Vitamin D might have a significant part in the immune system (Reinhardt and Hustmyer 1987). Production of 1,25-dihydroxyvitamin D3 locally by monocytes might be substantial in the immune system functions, especially in the parturient dairy cows.

\section{Clinical signs of vitamin D deficiency}

\section{Human}

The clinical feature of Vitamin D deficiency in human might be subtle. Patient with severe Vitamin D deficiency could presents with signs and symptoms of hypocalcaemia, while patient with mild deficiency might only has moderate decrease in serum Calcium concentrations, Phosphorus concentrations or both. Patients with moderate Vitamin D deficiency may often present with nonspecific symptoms such as pain, muscle weakness or decrease density of bones (Gloth et al 1995). ALP (Alkaline Phosphatase) and Parathyroid Hormone levels might be elevated; but not all Vitamin D deficient patients have elevated Parathyroid Hormone levels (Thomas et al 1998). By increasing intensity of Vitamin D deficiency, a secondary Hyperparathyroidism probably develops, leading to increase "bone turnover" combined with decrease mineralization of newly-formed bones that could be progressed to fractures and frank Osteomalacia (Boonen et al 1996). However in childes, Rachitic Growth Plates are mostly seen. Specific pediatric population might be at higher risk of Vitamin D deficiency predominantly related to sun exposure, skin pigmentation, consuming drugs and dietary factors (Lawson et al 1999).

Horses

Osteochondrosis in horses is characterized by unsuccessful vascularization of the proximal metaphysis of the tibiotrasus and the tarsal metatarsus. This condition spontaneously occurs, but it also can be existed in acidotic animals that reducing the conversion of 1-hydroxylation of 25-dihydroxyvitamin D3. The incidence and the intensity of Osteochondrosis could be both reduced by treatment with 1,25-dihydroxyvitamin D3 1 $\alpha$-hydroxyvitamin D3, but not through higher concentrations of Vitamin D alone (Azarpeykan et al 2016; Uhl 2018). 


\section{Cattle}

Vitamin D deficiency in beef cattle it considered very unlikely, when animals fed a deficient diet, and they are not exposure to sunlight, cattle showed clearly signs of vitamin $D$ deficiency when it feed a diet deficient to this vitamin and they are not exposure to direct sunlight within six to ten months. The clinical symptoms of vitamin $D$ deficiency in dairy cattle are resembled to signs of rickets in calves. The animals start to show stiffness in the joints and limbs, which make the walk is difficult, and then animal lie down and get up (Wallis 1944). Rickets and osteomalacia lesions in cattle are similar to those occur in other species of animals, the bones which soft and there is enlargement in growth plates where it is irregular due to stretching of the hypertrophic cartilage with tongues of cartilage that which extension to the metaphysic (Dittmer and Thompson 2011). Also because fractures of vertebrae the posterior paralysis which reported (Thompson and Cook 1987).

\section{Sheep and Goats}

The most significant influence of vitamin D deficiency in farm animal is decreased productivity. Decreased appetite and efficiency of utilization of food which caused mostly poor weight gain in newly growing livestock with poor productivity in adults. The effectiveness of reproduction is also decrease causing severe economic losses. When the disease is developed, lameness is the most noticeable sign especially in forelegs combined in young animals with enlargement of joints and bending of long bones. In the late stage, clinical rickets might develop concurrently with Osteomalacia in adults (Constable et al 2017). Rickets in sheep characterized clinically by lameness, stiff gait, enlargement of joints (particularly the radiocarbal joints), bent legs or bowed, and poor weight gain with loss of (Van Saun 2004). Rickets is mostly occurred in recently weaned animals as a result of quick growth in this age and the dependency on grassland or crops only (Agarwal et al 2002).

\section{Dogs and Cats}

Dogs and feline are commonly feeding on flesh or Offal -based diet that doesn't contain Vitamin D supplementation, the Fibrous Osteodystrophy is occur rather than Rickets, that attributable to secondary nutritional Hyperparathyroidism (Thompson 2007).

\section{Necropsy Findings}

In young animals, the most pathological changes are those of rickets, whereas an Osteomalacia is seen in older animals. However in all ages, variable degrees of Osteodystrophia Fibraosa might be developed and the distinction of the origin of these cellular changes is impractical based on gross and microscopic examination (Radostits et al 2007). A profile of nutrition and managemental factors are essential.

\section{Clinical Pathology}

Serum is the favored specimen in spite of the plasma (EDTA and Li-heparin) samples are acceptable (Ersfeld et al 2004). The measure of vitamin $D$ by immunoassay will be remaining the best method for reasons of convenience, quickness, turnaround and price (Wootton 2005). An obvious hypophosphatemia happen in early stages and is followed few months later with a fall in serum calcium. Serum alkaline phosphatase levels are typically raised (Radostits et al 2007).

\section{Treatment of vitamin D deficiency}

Basically, it is an accustomed administration of Vitamin $D$ in the dose rate set out under the following section (see section 2.8.1.9 Control). Affected animals must also be received sufficient Phosphorus and Calcium in feed (Constable et al 2017).

\section{Control of vitamin D deficiency}

Supplementation 
Supplementary giving of Vitamin $D$ for animals through injection or adding it into diet is essential when there is impracticable exposure to sunlight or inadequate amount of vitamin $D$ in natural ration. It is optimal providing animals with daily intake of $(7-12 \mathrm{lU} / \mathrm{kg})$ of body weight. Sun dried straw is perfect sources of Vitamin D; however, greenish fodders are mostly lacking to Vitamin D. Some of specific fish liver oils rich in Vitamin D, but they are mainly subjected for impairment in storage especially regarding to Vitamin A. Fish liver oils have also defect in missing their Vitamins $D$ and $A$ at pre mingled feeds, break down of Vitamin $E$ in same feed while it became rancid with decreasing the bufferfat contents in milk. However, water soluble preparations of vitamins D and A does not afford these defects. Yeast dry irradiated is predominantly a cheaper and simpler way at supplementing Vitamin D on grain-mixed feed (Radostits et al 2007).

Injection

When dietary supplementation is not applicable, single IM dose of Vitamin D2 (Calciferol) in oil will protect ruminants for three to six months. A dose of $11000 \mathrm{lU} / \mathrm{kg}$ of body weight is recommended that maintaining an adequate Vitamin $D$ levels for three to six months. In adult non-pregnant sheep weighting around $50 \mathrm{~kg}$, a single intramuscular injection of $6000 \mathrm{lU} / \mathrm{kg}$ of body weight provides adequate levels of 25 -hydroxyvitamin D3 for three months (Smith and Wright 1985). When vitamin D3 is given by injection, it causes higher level of this vitamin in tissues and plasma more than when given orally, whereas intravenous injection provides more elevated in plasma levels compared with intramuscular injection (Hidiroglou et al 1984).

\section{Toxicity of vitamin D}

Despite of numerous beneficial effects of Vitamin $D$, excessive amount of it is toxic, causing wide range of soft tissue mineralization resultant on Hypercalcemia and Hyperphosphatemia (Murphy 2002). The animal with toxicity exhibits severe gastrointestinal signs, abnormalities in rhythm of heart, hypertension, neurological symptom such as seizures, and death at last (Gunther et al 1988). Therefore, Cholecalciferol has been used as a pesticide in some countries. The pathogenesis of Cholecalciferol toxicity is not yet completely understood, because 1,25-dihydroxyvitamin D3 concentration is commonly normal when serum 25 -hydroxyvitamin D concentration is ten to twenty folds higher from the naturalistic extent (Scheftel et al 1991). It is imaginable that elevated concentration of 25-hydroxyvitamin D activate the Vitamin D receptors stimulating transcription of gene for Vitamin D-reacting gene or that higher concentration of all metabolites for Vitamin $\mathrm{D}$ overcomes the protein binding to Vitamin $\mathrm{D}$, releasing the free 1,25dihydroxyvitamin D3, that then enters the cells leading to stimulate gene transcription (Jones 2008).

\section{Rickets}

Rickets is chronic metabolic disorder of younger growing calves, as well as other ruminants, suffering from Vitamin D deficiency, unlike Osteomalacia, which is also a chronic disorder of older cattle suffering from Phosphorus deficiency. The bones diaphysis are border and shorter than the normal with increased cortices width. Lameness is the characteristic sign of rickets and the animal will respond Vitamin D injection in early stage of the disease (Duncanson 2013).

\section{Pathogenesis of rickets}

Rickets features are comparable in all species. Rickets lesions are more acute in bones fastest growing that include; the tibia, radius, metatarsals and metacarpals (Nisbet et al 1966). Based on the radiography and the necropsy finding, dilation of the physeal outgrowth plate is the most obvious change (Klein 1999). Raiographically, other abnormalities may be seen such as: flaring of metaphyseal, the cortex will be thin, pathological fractures and general weak mineralization (McCarthy and Frassica 1998). Moreover, post-mortem examination might exhibit an irregular thickness of the physeal cartilage, collapse of subchondral bone producing erosion of articular cartilage, and spontaneous fractures. Costochondral junctions enlargements (rachitic rosary) are also chronic lesions of rickets that might be showed on radiography or in necropsy finding (Dittmer and Thompson 2011). Damaged provisional cartilage calcification at site of endochondral ossification leads to accumulate of hypertrophic chondrocytes, resulting in 
thickened and irregular growth plate with tongues and islands of chondrocytes that extend to the metaphyses (Thompson 2007). Same changes may occur down articular epiphyseal of young animals. However, other cellular alterations might comprise the solid osteoid seams lining trabiculae and dis-organized or lack to rudimentary spongiosa (Adams 2018). Signs of trauma and hemorrhage might be show in metaphyses and rudimentary spongiosa, because of damage the weak trabeculae for bones with poor mineralization (Bonniwell et al 1988).

\section{Clinical finding of rickets}

Rickets is manifested by solidity of the walk, Enlarged joints of the extremities (particularly in forelegs), and the Costochondral junction enlargement. In addition, long bones show seedy curvatures, mostly outward and forward at the carpus in cattle and sheep. Lameness with inclination to lie down for prolonged interval is also seen. About $50 \%$ of lambs was found to be influenced during rickets outbreak (Bonniwell et al 1988). Increase tendencies for bones fracture, arching back and constriction usually to the stage of actual collapse of the pelvis are probably occurred.

A history to dietary insufficiency of each of Vitamin D, Phosphorus or Calcium will back the clinical diagnosis. Radiographic examination that proofed expanded and unequal physes suggest Rickets. Similar clinical, radiographic and pathological findings of rickets have been recorded in young cattle below one year of age suffering from copper deficiency. Plasma and liver concentration of copper are decreased and there is evidence of dietary deficiency for copper (Radostits et al 2007).

\section{Treatment and control of rickets}

Treatment is recommended of the individually dietary lacking including Vitamin D, Phosphorus and Calcium that presenting beneath their respective heading. Mild distortions will get well with appropriate treatment, whereas gross distortions mostly continue. General condition and appetite amelioration occur quickly which is combined with returning the normal levels of Phosphorus and ALP. Rickets could be successfully treated in lambs by parenteral administration of Vitamin D3, Vitamin A, Calcium Borogluconate solution including Phosphorus and Magnesium, and diet supplementation with protein and bone meal that resulting in a marked response. However, animal with recumbency may predominantly walk during some days (Radostits et al 2007; Constable et al 2017).

\section{Final Considerations}

Vitamin D is extremely involved in Calcium/Phosphorus absorption and hemostasis that plays a vital role of bone formation and remodeling. Vitamin D has advantages as an anti-inflammatory and an immune-modulating factor; these properties are vital for defense against infectious diseases and could probably be one of many factors that makes people resistant against contagious diseases such as hemorrhagic septicemia and Corona Virus (Covid-19). However, in sufficient exposure to UVB irradiation and/or lack of dietary vitamin D could induce a vitamin D deficiency in farm animals as well as humans, which clinically characterized by poor appetite and growth those in advanced cases leads to osteomalacia and osteodystrophy. In addition, wide-ranges of non-skeletal disorders with neoplastic, cardiovascular and autoimmune diseases are caused as a result of vitamin D deficiency. A deficiency of the active form of vitamin D due to genetic or environment; might be resulted in rickets or osteomalacia secondary to hypophosphatemia and hypocalcemia which probably leads to hyperparathyroidism and concurrent osteodystrophy.

\section{Acknowledgements}

This review did not received grant from any institutional, commercial and non-profit-sectors agencies. The current review is completed by the authors themselves.

\section{Conflict of Interest}

No conflicts of interest are declared by the authors. 


\section{References}

Abbott K (2018) The Practice of Sheep Veterinary Medicine. University of Adelaide Press, USA.

Abboud M, Rybchyn M, Rizk R, Fraser D, Mason R (2017) Sunlight exposure is just one of the factors which influence vitamin D status. Photochemical and Photobiological Sciences 16:302-313.

Adams JE (2018) Radiology of rickets and osteomalacia Vitamin D. Elsevier.

Agarwal K, Mughal M, Upadhyay P, Berry J, Mawer E, Puliyel J (2002) The impact of atmospheric pollution on vitamin D status of infants and toddlers in Delhi, India. Archives of Disease in Childhood 87:111-113.

Anderson PH, Atkins GJ (2008) The skeleton as an intracrine organ for vitamin D metabolism. Molecular Aspects of Medicine 29:397-406.

Azarpeykan S, Dittmer K, Gee E, Marshall J, Wallace J, Elder P, Acke E, Thompson K (2016) Influence of blanketing and season on vitamin $\mathrm{D}$ and parathyroid hormone, calcium, phosphorus, and magnesium concentrations in horses in New Zealand. Domestic Animal Endocrinology 56:75-84.

Ball GF (2013) Vitamin D. In: Bioavailability and analysis of vitamins in foods. Springer-Science and Business Media, B.V.

Barsony J, Prufer K (2002) Vitamin D receptor and retinoid X receptor interactions in motion. Vitamins and Hormones 65:345-376.

Bikle D (2009) Nonclassic actions of vitamin D. The Journal of Clinical Endocrinology \& Metabolism 94:26-34.

Bonniwell M, Smith B, Spence J, Wright H, Ferguson D (1988) Rickets associated with vitamin D deficiency in young sheep. The Veterinary Record 122:386-388.

Boonen S, Aerssens J, Dequeker J (1996) Age-related endocrine deficiencies and fractures of the proximal femur. II implications of vitamin D deficiency in the elderly. Journal of Endocrinology 149:13-17.

Boros S, Bindels RJ, Hoenderop JG (2009) Active Ca2+ reabsorption in the connecting tubule. Pflügers Archiv-European Journal of Physiology 458:99-109.

Bouillon R (2001) Vitamin D: Photosynthesis, metabolism, and action to clinical applications. In: DeGroot LJ (ed) Endocrinology. Philadelphia: W.B. Saunders, pp. 1009-1028.

Bouillon R, Van Cromphaut S, Carmeliet G (2003) Intestinal calcium absorption: molecular vitamin D mediated mechanisms. Journal of Cellular Biochemistry 88:332-339.

Boyce BF, Xing L (2008) Functions of RANKL/RANK/OPG in bone modeling and remodeling. Archives of Biochemistry and Biophysics 473:139-146.

Canaff L, Hendy GN (2002) Human calcium-sensing receptor gene Vitamin D response elements in promoters P1 and P2 confer transcriptional responsiveness to 1, 25-dihydroxyvitamin D. Journal of Biological Chemistry 277:3033730350.

Constable P, Hinchcliff K, Done S, Gruenberg W (2017) A textbook of the diseases of cattle, horses, sheep, pigs, and goats. WB Saunders, Madrid.

Dittmer K, Thompson K (2011) Vitamin D metabolism and rickets in domestic animals: a review. Veterinary Pathology 48:389-407.

Duncanson GR (2013) Farm Animal Medicine and Surgery: For Small Animal Veterinarians: Cabi.

Dusso A, Brown AJ, Slatopolsky E (2005) Vitamin D. American Journal of Physiology-Renal Physiology 289:8-28.

Dusso AS, Thadhani R, Slatopolsky E (2004) Vitamin D receptor and analogs. Paper presented at the Seminars in nephrology.

Dusso AS, Slatopolsky E (2005) Vitamin D. Am J Physiol Renal Physiol 289:8-28.

Elder CJ, Bishop NJ (2014) Rickets. The Lancet 383:1665-1676.

Engstrom G, Goff J, Horst R, Reinhardt T (1987) Regulation of calf renal 25-hydroxyvitamin D-hydroxylase activities by calcium-regulating hormones. Journal of Dairy Science 70:2266-2271. 
Ersfeld DL, Rao DS, Body JJ, Sackrison Jr JL, Miller AB, Parikh N, Eskridge TL, Polinske A, Olson GT, MacFarlane GD (2004) Analytical and clinical validation of the $25 \mathrm{OH}$ vitamin D assay for the LIAISON ${ }^{\circledR}$ automated analyzer. Clinical Biochemistry 37:867-874.

Feldman D, Glorieux F, Pike J (1997) Vitamin D: Vitamin D metabolism. In: Reinhardt TA (ed). Academic Press: San Diego.

Feldman D, Krishnan AV, Swami S (2013) Vitamin D: biology, actions, and clinical implications Osteoporosis. Elsevier.

Freeman L, Evans K, Hughes S, Moss P, Chakraverty R, Hewison M (2003) Differential regulation of vitamin D receptor and its ligand in human dendritic cells: A paracrine mechanism for regulation of antigen presentation. Paper presented at the 22nd Joint Meeting of the British Endocrine Societies.

Fritsche J, Mondal K, Ehrnsperger A, Andreesen R, Kreutz M (2003) Regulation of 25-hydroxyvitamin D3-1 $\alpha$ hydroxylase and production of $1 \alpha, 25$-dihydroxyvitamin D3 by human dendritic cells. Blood 102:3314-3316.

Glorieux FH, Pettifor JM (2014) Vitamin D/dietary calcium deficiency rickets and pseudo-vitamin D deficiency rickets. Bone Key Reports 3:524.

Gloth FM, Gundberg CM, Hollis BW, Haddad JG, Tobin JD (1995) Vitamin D deficiency in homebound elderly persons. Jama 274:1683-1686.

Goff JP, Horst RL, Littledike ET (1982) Effect of the maternal vitamin D status at parturition on the vitamin D status of the neonatal calf. The Journal of Nutrition 112:1387-1393.

Goff JP, Horst RL, Littledike ET (1984) Effect of sow vitamin D status at parturition on the vitamin D status of neonatal piglets. The Journal of Nutrition 114:163-169.

Goltzman D, Miao D, Panda DK, Hendy GN (2004) Effects of calcium and of the Vitamin D system on skeletal and calcium homeostasis: lessons from genetic models. The Journal of Steroid Biochemistry and Molecular Biology 89:485489.

Gunther R, Felice L, Nelson RK, Franson AM (1988) Toxicity of a vitamin D3 rodenticide to dogs. Journal of the American Veterinary Medical Association 193:211-214.

Handel I, Watt KA, Pilkington JG, Pemberton JM, Macrae A, Scott P, McNeilly TN, Berry JL, Clements DN, Nussey DH (2016) Vitamin D status predicts reproductive fitness in a wild sheep population. Scientific Reports 6:18986.

Heaney RP (2005) Vitamin D: role in the calcium economy. In: Feldman D, Pike JW, Glorieux FH (eds). San Diego, California: Elsevier, pp. 773-787.

Hendy G, Hruska K, Mathew S, Goltzman D (2006) New insights into mineral and skeletal regulation by active forms of vitamin D. Kidney international 69:218-223.

Hidiroglou M, Proulx J, Roubos D (1979) 25-hydroxyvitamin D in plasma of cattle. Journal of Dairy Science 62:10761080.

Hidiroglou M, Shorrock C, Williams C (1984) Vitmain D3 response in sheep to oral versus parenteral administration and to intramuscular dose levels of vitamin D3. Canadian Journal of Animal Science 64:697-707.

Hoenderop JG, Nilius B, Bindels RJ (2005) Calcium absorption across epithelia. Physiological Reviews 85:373-422.

Holick M (1994) Vitamin D-new horizons for the 21st century. McCollum award lecture. The American Journal of Clinical Nutrition 60:619-630.

Holick M (1999) Vitamin D: photobiology, metabolism of action, and clinical applications. In: F MJ (ed), Primer on the Metabolic Bone Diseases 4rd edn. Lippincott Williams \& Wilkins, Philadelphia, pp. 92-98.

Holick MF (2002) Vitamin D: the underappreciated D-lightful hormone that is important for skeletal and cellular health. Current Opinion in Endocrinology, Diabetes and Obesity 9:87-98.

Holick MF (2006a) Resurrection of vitamin D deficiency and rickets. The Journal of Clinical Investigation 116:20622072.

Holick MF (2006b) Vitamin D: its role in cancer prevention and treatment. Progress in Biophysics and Molecular Biology 92:49-59.

Holick MF (2007) Vitamin D deficiency. New England Journal of Medicine 357:266-281.

Jones G (2008) Pharmacokinetics of vitamin D toxicity. The American Journal of Clinical Nutrition 88:582S-586S. 
Jones G, Strugnell SA., DeLuca HF (1998) Current understanding of the molecular actions of vitamin D. Physiological Reviews 78:1193-1231.

Kimmel-Jehan C, Darwish HM, Strugnell SA, Jehan F, Wiefling B, DeLuca HF (1999) DNA bending is induced by binding of vitamin $D$ receptor-retinoid $X$ receptor heterodimers to vitamin $D$ response elements. Journal of Cellular Biochemistry 74:220-228.

Kitazawa S, Kajimoto K, Kondo T, Kitazawa R (2003) Vitamin D3 supports osteoclastogenesis via functional vitamin D response element of human RANKL gene promoter. Journal of Cellular Biochemistry 89:771-777.

Klein GL (1999) Nutritional rickets and osteomalacia. In: Favus M (ed), Primer on the Metabolic Bone Diseases 4rd edn. Lippincott Williams \& Wilkins, Philadelphia, pp. 315-319.

Kondo T, Kitazawa R, Maeda S, Kitazawa S (2004) 1 $\alpha, 25$ dihydroxyvitamin D3 rapidly regulates the mouse osteoprotegerin gene through dual pathways. Journal of Bone and Mineral Research 19:1411-1419.

Lawson M, Thomas M, Hardiman A (1999) Dietary and lifestyle factors affecting plasma vitamin D levels in Asian children living in England. European Journal of Clinical Nutrition 53:268-272.

Mason R, Sequeira V, Gordon-Thomson C (2011) Vitamin D: the light side of sunshine. European Journal of Clinical Nutrition 65:986.

Masuyama R, Stockmans I, Torrekens S, Van Looveren R, Maes C, Carmeliet P, Bouillon R, Carmeliet G (2006) Vitamin $\mathrm{D}$ receptor in chondrocytes promotes osteoclastogenesis and regulates FGF23 production in osteoblasts. The Journal of Clinical Investigation 116:3150-3159.

McCarthy EF, Frassica FJ (1998) Pathology of bone and joint disorders. With clinical and radiographic correlation. Philadelphia: WB Saunder 195-269.

McDowell L (2000) Reevaluation of the metabolic essentiality of the vitamins-review. Asian-Australasian Journal of Animal Sciences 13:115-125.

Meyer MB, Watanuki M, Kim S, Shevde NK, Pike JW (2006) The human transient receptor potential vanilloid type 6 distal promoter contains multiple vitamin D receptor binding sites that mediate activation by 1,25 -dihydroxyvitamin D3 in intestinal cells. Molecular Endocrinology 20:1447-1461.

Milgram J (1990) Renal osteodystrophy Radiologic and Histologic Pathology of Nontumorous Diseases of Bones and Joints. Northbrook Publishing Company Co, Inc, Northbrook, IL,.

Miller WL, Portale AA (2000) Vitamin D 1 $\alpha$-hydroxylase. Trends in Endocrinology and Metabolism 11:315-319.

Murphy MJ (2002) Rodenticides. The Veterinary clinics of North America. Small Animal Practice 32:469-484.

Naja RP, Dardenne O, Arabian A, St. Arnaud R (2009) Chondrocyte-specific modulation of Cyp27b1 expression supports a role for local synthesis of 1, 25-dihydroxyvitamin D3 in growth plate development. Endocrinology 150:4024-4032.

Nisbet D, Butler E, Smith B, Robertson J, Bannatyne C (1966) Osteodystrophic diseases of sheep. 2. Rickets in young sheep. Journal of Comparative Pathology 76:159-169.

Panda DK, Miao D, Bolivar I, Li J, Huo R, Hendy GN, Goltzman D (2004) Inactivation of the 25-hydroxyvitamin D 1 $\alpha$ hydroxylase and vitamin $D$ receptor demonstrates independent and interdependent effects of calcium and vitamin $D$ on skeletal and mineral homeostasis. Journal of Biological Chemistry 279:16754-16766.

Quarles LD (2012) Role of FGF23 in vitamin D and phosphate metabolism: implications in chronic kidney disease. Experimental Cell Research 318:1040-1048.

Rachez C, Freedman LP (2000) Mechanisms of gene regulation by vitamin D3 receptor: a network of coactivator interactions. Gene 246:9-21.

Radostits O, Gay C, Hinchcliff K, Constable P (2007) Veterinary Medicine: A Textbook of the diseases of Cattle, Sheep, Pigs, Goats and Horses. Saunders, Elsever.

Reichrath J, Friedrich M, Tilgen W (2003) Vitamin D analogs in cancer prevention and therapy. Springer Science \& Business Media.

Reinhardt TA, Hustmyer, FG (1987) Role of vitamin D in the immune system. Journal of Dairy Science 70:952-962.

Scheftel J, Setzer S, Walser M, Pertile T, Hegstad R, Felice L, Murphy, M (1991) Elevated 25-hydroxy and normal 1, 25dihydroxy cholecalciferol serum concentrations in a successfully-treated case of vitamin D3 toxicosis in a dog. Veterinary and Human Toxicology 33:345-348. 
Smith B, Wright H (1985) Effect of parenteral vitamin D3 on plasma 25-hydroxyvitamin D3 concentration in sheep. Research in Veterinary Science 39:59-61.

St-Arnaud R (2008) The direct role of vitamin D on bone homeostasis. Archives of Biochemistry and Biophysics 473:225-230.

Suda T (2003) Ueno Y, Fujii K, and Shinki T. Vitamin D and bone. Journal of Cellular Biochemisrty 88:259-266.

Suzuki Y, Landowski CP, Hediger MA (2008) Mechanisms and regulation of epithelial Ca2+ absorption in health and disease. Annual Review of Physiology 70:257-271.

Takeda S, Yoshizawa T, Nagai Y, Yamato H, Fukumoto S, Sekline K, Kato S, Matsumoto T, Fujita T (1999) Stimulation of osteoclast formation by 1,25 -dihydroxyvitamin $D$ requires its binding to vitamin $D$ receptor (VDR) in osteoblastic cells: studies using VDR knockout mice. Endocrinology 140:1005-1008.

Thomas MK, Lloyd-Jones DM, Thadhani RI, Shaw AC, Deraska DJ, Kitch BT, Vamvakas E C, Dick IM, Prince RL, Finkelstein JS (1998) Hypovitaminosis D in medical inpatients. New England Journal of Medicine 338:777-783.

Thompson K (2007) Bones and joints. In: Jubb K, Kennedy P (eds) Pathology of Domestic Animals 5rd edn. M. Grant Maxie Ed., Saunders.

Thompson K, Cook T (1987) Rickets in yearling steers wintered on a swede (Brassica napus) crop. New Zealand Veterinary Journal 35:11-13.

Uhl EW (2018) The pathology of vitamin D deficiency in domesticated animals: an evolutionary and comparative overview. International Journal of Paleopathology 23:100-109.

van Abel M, Hoenderop JG, Dardenne O, Arnaud RS, van Os CH, van Leeuwen HJ, Bindels, RJ (2002) 1, 25Dihydroxyvitamin D3-independent stimulatory effect of estrogen on the expression of ECaC1 in the kidney. Journal of the American Society of Nephrology 13:2102-2109.

van Abel M, Hoenderop JG, van der Kemp AW, van Leeuwen JP, Bindels RJ (2003) Regulation of the epithelial Ca2+ channels in small intestine as studied by quantitative mRNA detection. American Journal of PhysiologyGastrointestinal and Liver Physiology 285:78-85.

Van Saun RJ (2004) Vitamin D-responsive rickets in neonatal lambs. The Canadian Veterinary Journal 45:841.

Wallis G (1944) Vitamin D deficiency in dairy cows. South Dakota Agriculture Experiment Station Bulletin 372.

Wolf M, Thadhani R (2007) Beyond minerals and parathyroid hormone: Role of active vitamin $D$ in end-stage renal disease (vol 18, pp 302). Paper presented at the Seminars in Dialysis.

Wootton AM (2005) Improving the measurement of 25-hydroxyvitamin D. Clinical Biochemist Reviews 26:33.

Yagci A, Werner A, Murer H, Biber J (1992) Effect of rabbit duodenal mRNA on phosphate transport in Xenopus laevis oocytes: dependence on 1,25-dihydroxy-vitamin-D3. Pflügers Archiv 422:211-216.

Zittermann A (2003) Vitamin D in preventive medicine: are we ignoring the evidence. British Journal of Nutrition 89:552-572. 